Table 1

Mean Changes in Heart Rate During Adaptation, Conditioning, Test Trials*

\begin{tabular}{lcccrc}
\hline Condition & Adaptation & Conditioning & Test & l. (df $=2 / 30)$ & $\mathrm{p}$ \\
\hline$\Delta \mathrm{HR}-\mathrm{Sh}$ & $1.466^{\mathrm{a}}$ & $2.097^{\mathrm{b}}$ & $2.428_{\mathrm{b}}$ & 7.20 & $<.05$ \\
$\Delta \mathrm{HR}-\mathrm{NoSh}$ & $0.733_{\mathrm{a}}$ & $1.514_{\mathrm{b}}$ & $1.868_{\mathrm{b}}$ & 10.17 & $<.05$ \\
No $\Delta \mathrm{HR}-\mathrm{Sh}$ & $1.533_{\mathrm{a}}$ & $1.375_{\mathrm{a}}$ & $1.559_{\mathrm{a}}$ & .30 & NS \\
\hline
\end{tabular}

* Means within cach row haling subscripts in common are not significantly different from each other.

$(\mathrm{F}=3.105, \mathrm{df}=4 / 30, \mathrm{p}<.05)$. Table 1 shows mean heart-rate changes observed during adaptation, conditioning, and test trials in the three conditions. Simple effects tests show that there were significant differences between trials in the experimental condition ( $\Delta$ HR-Sh) and in one of the control conditions ( $\triangle$ HR-NoSh). In both of these conditions, Newman-Keuls tests reveal that the conditioning trials did not differ from the test trials. while both were significantly different from adaptation trials. These results can be taken to indicate that conditioning was accomplished for the experimental Os ( $\Delta \mathrm{HR}-\mathrm{Sh})$ and for Os who heard changes in the heart rate of an individual ostensibly engaged in exercises ( $\Delta$ HR-NoSh). No differences between adaptation, conditioning, and test trials were found for Os who heard a person being shocked but whose heart rate remained constant (NoدHR-Sh).

\section{DISCUSSION}

In general, the results suggest that changes in another person's heart rate can be salient cues of his emotional reaction and, as such, be a basis for the occurrence of vicarious emotional instigation and the conditioning of the O's own heart rate. However, on the basis of the present results, it appears that heart rate was not sufficient to produce vicarious conditioning of the galvanic skin response.

No systematic attempt was made to analyze cognitive processes of Os. However, one interesting observation can be made from postexperimental interviews. Os in conditions involving shock often stated that they quickly forgot about the "S" and were not concerned about him. However, those in Condition $\triangle$ HR-NoSh reported that they actively thought about the " $S$ " throughout the experiment, picturing and imagining what exercises he was doing.

Since no shock is mentioned in Condition $\triangle \mathrm{HR}-\mathrm{NoSh}$, it is notable that Os in this condition were successfully conditioned, while those in Condition No $\Delta$ HR-Sh were not. On early trials, Os in Condition No $\Delta$ HR-Sh showed greater responsiveness to the $\mathrm{CS}$ than $\mathrm{Os}$ in Condition $\triangle$ HR-NoSh: however, these early responses emitted on adaptation trials were not significantly different from their responses to the CS following training. On the other hand. during adaptation trials, Os in Condition $\triangle \mathrm{HR}-\mathrm{NoSh}$ showed little reaction to the $C S$, but after presentation of the CS-UCS pairings, their responses became as strong as those in Condition $\Delta$ HR-Sh.

It appears that a form of socially mediated heart-rate conditioning was achieved in the present experiment. The manipulation that established the situation as either aversive or nonaversive had a significant effect on both physiological and cognitive processes. It affected the sensitivity of Os during adaptation trials and their cognitive work throughout the experiment. It is also evident that of the two cues presented, heart rate and shock, heart rate was the more important and had more pronounced effects. When heart rate was consistent with the information presented by the $\mathrm{F}$, heart-rate conditioning occurred. However, discrepancy between

\section{P. S. DELIN and J. H. BUXTON, University of Adelaide, Adelaide, South Australia 5001}

A list of 10 noun paired associates was learned by three groups of $S s$ under conditions $R T T, R T R$, and $R T$. An additional test trial was given a week later. The results suggest that once a correct response can be produced, further test trials facilitate future recall as much as do further reinforced trials.

As early as $1926, \mathrm{Pal}$ demonstrated that the learning of verbal material is facilitated by the interpolation of test $(\mathrm{T})$ trials in a series of reinforced (R) trials. More recently, Estes (1960) investigated the effect of interpolated $\mathbf{T}$ trials and concluded that they improved retention by providing an opportunity for responses learned on prior $\mathrm{R}$ trials to become conditioned to more stimuli. Izawa (1969), after a series of studies comparing the effects of $T$ and $R$ trials in paired-associate learning, concluded that interpolated heart-rate cues and instructional set apparently prevented conditioning.

\section{REIERENCES}

BANDL:RA, A., \& ROSENTHAL, T. L. Vicarious classical conditioning as a function of arousal level. Journal of Personality \& Social Psychology, 1966, 3, 54-62.

BERGER, S. M. Conditioning through vicarious instigation. Psychological Review, 1962, 69, 450-466.

CRAIG, K., \& LOWERY, J. Heart rate components of conditioned vicarious autonomic response. Journal of Personality \& Social Psychology, 1969, 11, 381-387.

LAZARUS, R., SPIESMAN, J., MORDKOFF, A., \& DAVISON, L. A laboratory study of psychological stress produced by a motion picture film. Psychological Monographs, 1962, 76.

SCHACHTER, S., \& SINGER, S. Cognitive, social, and physiological determinants of emotional state. Psychological Review, 1962 69, 379-399.

VALINS, S. Cognitive effects of false heart-rate feedback. Journal of Personality \& Social Psychology, 1966, 4, 400-408.

WOOD, D., \& OBRIST, P. Effects of controlled and uncontrolled respiration on the conditioned heart rate response in humans. Joumal of Experimental Psychology, 1964, $68,221-229$.

1. The author wishes to express her indebtedness to Dr. Robert B. Zajonc for his guidance and support. The author would also like to thank Michael Hayes who acted as stooge and provided assistance in collection of the data.

\title{
Uverlearning of paired associates as a function of test and reinforced trials
}

$T$ trials arrest the forgetting that would normally occur between $\mathrm{R}$ trials separated by the same interval and potentiate the conditioning effect of subsequent reinforcements.

Subjective reports from Ss in experiments on mnemonics and explicit mediation (e.g., Delin, 1968, 1969a,b) suggested the possibility that, when material was highly meaningful and presentation times were long, $T$ trials might carry out a more active role in learning. Ss spontaneously reported that they used explicit mediators to get the material "into their heads," and that once this was done the learning was consolidated by outputting the material. Some Ss further reported that once the explicit mediator was constructed, subsequent presentations of the response item were treated, not as new information, but simply as confirmation of the previous learning, and that once they were sure they knew the material they hardly bothered to look at the memory drum.

These reports are consistent with the findings of Olton (1966) and Delin (1969) 
which suggest that explicit mediation has its primary effect on acquisition rather than on retention. They are also consistent with the findings of Adams \& McIntyre (1967) to the effect that once material has been learned using explicit mediation, the Ss gradually stop using the mediator in the course of subsequent recallings of the items.

These observations suggest that under conditions that facilitate the use of explicit mediation (e.g., material highly meaningful and presentation times longer than $4 \mathrm{sec}$ ) $\mathrm{T}$ trials should improve long-term retention rather than being neutral with respect to it. The present study attempts to verify this by comparing the effect of a $T$ trial with that of an $\mathrm{R}$ trial upon the later recall of items learned to the point where they could be produced as responses in a paired-associate task.

\section{METHOD}

Two lists of paired associates were used, a practice list of five letter-number pairs and an experimental list of 10 paired nouns, selected from those used by Delin (1969b) and arranged so that all pairs had low-rated interitem association.

The Ss, 48 first-year psychology students, were run individually. The material was self-presented at a 7 -sec rate by moving a window in a manila folder over a preprinted sheet. Intertrial interval was approximately $20 \mathrm{sec}$ throughout.

Each $S$ first received four trials on the practice list in the sequence RTRT. The score obtained on the second $T$ trial was used to produce a rough matching of the $\mathrm{Ss}$ into the three experimental groups, the matching being intended to reduce the likelihood of gross between-groups differences in learning ability. Having been assigned to an experimental group, the $S$ was told that the experiment was intended to discover something about verbal learning and not about his own ability. He was asked to do his best but cautioned against overmotivation.

The differences between the three experimental groups were that Group A received three trials in the sequence RTT, Group B received three trials in the sequence RTR, and Group C received two trials in the sequence RT. In order to equalize response familiarization between groups $\mathrm{A}$ and $\mathrm{B}, \mathrm{Ss}$ were required to say the response words aloud on all trials. The lists were presented in a different random order on each trial, but these orderings did not differ between $S$ s. In a second session 1 week after the first, each $S$ received one $T$ trial. Until this trial was completed, Ss were given no feedback as to their performance.

\section{RESULTS}

Table 1 shows the means, medians, and

Table 1

Summary of Data on $T_{1}$. Ret, and P(Ret $\left.T_{1}\right)$

\begin{tabular}{|c|c|c|c|c|c|c|c|c|c|}
\hline & \multicolumn{3}{|c|}{ Group A (RTT-T) } & \multicolumn{3}{|c|}{ Group B (RTR-T) } & \multicolumn{3}{|c|}{ Giroup ( ( $\mathrm{RT}-\mathrm{I})$} \\
\hline & Mean & Mdn. & SI) & Mean & $M d n$ & $\mathrm{Sl}$ & Me:an & $M \mathrm{dn}$ & $51)$ \\
\hline Correct on $\mathrm{T}_{1}$ & 6.88 & 7.5 & 2.32 & 6.44 & 6.5 & 2.62 & 7.31 & 7.0 & 2.59 \\
\hline Correct on Ret & 5.06 & 5.5 & 2.56 & 6.00 & 6.0 & 2.47 & 3.69 & 4.0 & 2.79 \\
\hline$P\left(\operatorname{Ret} / \mathrm{T}_{1}\right)$ & .74 & .79 & .24 & .71 & .78 & .26 & .46 & .50 & .28 \\
\hline
\end{tabular}

SDs for the three experimental groups on three variables: numbers of correct responses on $T_{1}$ and the retention test (Ret), and $P\left(\operatorname{Ret} \mid T_{1}\right)$, the proportion of items correct on $T_{1}$ that were also correct on Ret. The means on $T_{1}$ did not differ significantly. An analysis of variance gave an $F$ ratio of .46 (for $\mathrm{df}=2 / 45$ ), so the groups may be regarded as comparable in initial performance. A similar analysis of the Ret scores also proved insignificant at the .05 level $(\mathrm{F}=3.00, \mathrm{df}=2 / 45$, $\mathrm{F}=3.20$ )

Since the $P\left(\operatorname{Ret} \mid T_{1}\right)$ scores were clearly not normal, they were analyzed by means of a Kruskal-Wallace test. This proved significant at the .02 level $(H=8.05)$. Mann-Whitney U tests comparing Groups A and $B$ with $C$ also proved significant, producing Uvalues of 60.5 and 65.0 $(p<.02)$.

\section{DISCUSSION AND CONCLUSIONS}

The analysis of the $P\left(\operatorname{Ret} \mid T_{1}\right)$ scores clearly suggests that either a $T$ trial or an $R$ trial will increase the probability that an item that has been correctly produced as a response will again be correctly produced on a later $T$ trial. There is nothing in our data to suggest any superiority in this regard for either $\mathbf{R}$ or $\mathrm{T}$. It is, of course dangerous to generalize on the basis of a failure to reach significance, and it may be that a repetition of the experiment on a larger scale would demonstrate a difference. Certainly it would be reasonable to expect that such a replication would produce significant between-groups differences in Ret scores.

Considered in relation to previous work on the effect of interpolated $\mathrm{T}$ trials, the present study raises a number of questions. Thus, although the result was not consistent with those of Izawa (1969), this could result, not from the differences in material and presentation time, but from the much greater retention interval used in this experiment. But this in turn raises grave doubts as to the propriety of the common practice (see Estes, 1960; Izawa, 1969) of stating hypotheses about the effects of different types of experimental treatment in terms of the probability of correct responding, without specifying when the responding is to take place.

These results also call into question the use of the term "reinforcement" that has been made in this paper. Our usage stems from that of Estes (1960), who argued for what he called the "neutral definition," identifying reinforcement with the operation that is supplied by the investigator in order to produce learning. The present study provides an example in which a treatment that we have described (following Estes) as a 'reinforced' trial appears to produce no more learning than what we have described (also following Estes) as a 'test' trial. In order to avoid finding ourselves asking such questions as whether or not test trials are as reinforcing as reinforced trials, and whether or not feedback on success during test trials might have proved reinforcing, it might be better to use an even more 'neutral' term than that selected by Estes, and substitute the term "presentation" for the term "R trial."

Further interpretation of the present result must wait upon the larger-scale replication of the study. Such replication should also explore the involvement of explicit mediation in the situation. The evidence so far available is still compatible with the view that once an explicit mediator is formed the only way an association can be strengthened is by outputting the item. The Ss in the present study could, in fact, have treated the $R$ trials as $\mathbf{T}$ trials.

\section{REFERENCES}

ADAMS, J. S., \& McINTYRE, J. S. Natural language mediation and all-or-none learning. Canadian Journal of Psychology, 1967, 21, 436-449.

DELIN, P. S. Success in recall as a function of success in implementation of mnemonic instructions. Psychonomic Science, 1968, 12 , 153-154.

DELIN, P. S. The effects of mnemonic instruction and list length on serial learning and retention. Psychonomic Science. 1969a, 17, 111-113.

DELIN, P. S. An experiment examining list-learning with and without the mnemonic use of bizarre associations. Journal of General Psychology, 1969b, 81, 249-260.

ESTES, W. K. Learning theory and the new "mental chemistry." Psychological Review, 1960, 67, 207-223.

IZAWA, C. Comparison of reinforcement and test trials in paired-associate learning. Journal of Experimental Psychology, 1969, 81, 600-603.

OLTON, R. M. The effect of a mnemonic upon the retention of paired associated verbal material. Unpublished doctoral dissertation, University of California, Berkeley, 1966.

PAL, G. Influence of reproducing process in memorization. Indian Journal of Psychology, $1926,1,39-44$. 